\title{
Coating of Tungsten Wire with Ni/Al Multilayers for Self-Healing Applications
}

\author{
Ana Sofia Ramos ${ }^{1, *}$ (D), Lukasz Maj ${ }^{2}$, Jerzy Morgiel ${ }^{2}$ and Maria Teresa Vieira ${ }^{1}$ \\ 1 CEMMPRE, Department of Mechanical Engineering, University of Coimbra, R. Luís Reis Santos, \\ 3030-788 Coimbra, Portugal; teresa.vieira@dem.uc.pt \\ 2 Institute of Metallurgy and Materials Science, Polish Academy of Sciences, Reymonta 25, 30-059 Cracow, \\ Poland; 1.maj@imim.pl (L.M.); j.morgiel@imim.pl (J.M.) \\ * Correspondence: sofia.ramos@dem.uc.pt; Tel.: +351-239790701
}

Received: 3 October 2017; Accepted: 14 December 2017; Published: 19 December 2017

\begin{abstract}
Self-healing materials are able to partially or completely reverse the damage inflicted on them. The possibility of self-healing mechanical and chemical failures that occur during service will improve the lifetime and reliability of structural materials. For this purpose, two main steps must be considered: (i) detection, and (ii) repairing (healing) of cracks. The exothermic character of reactive multilayers has potential for self-healing applications, namely in the healing step. In this context, $\mathrm{Ni}(\mathrm{V}) / \mathrm{Al}$ multilayer thin films were deposited onto tungsten wires by magnetron sputtering from two targets. A detailed microstructural characterization was carried out by scanning and transmission electron microscopy after deposition, as well as after ignition by applying an electrical discharge. The as-deposited films presented an irregular layered structure with local defects not observed for flat substrates, although $\mathrm{Ni}$ - and Al-rich nanolayers could be distinguished. The as-reacted films were constituted by $\mathrm{Al}_{3} \mathrm{Ni}_{2}$ grains with $\mathrm{Al}_{3} \mathrm{~V}$ phase at the grain boundaries. In order to use reactive multilayers for self-healing purposes, the heat released must be maximised by improving the microstructure of the nanolayered films. Nevertheless, after ignition, the $\mathrm{Ni}(\mathrm{V}) / \mathrm{Al}$ multilayer films deposited onto $\mathrm{W}$ wire underwent a self-sustained reaction, releasing heat.
\end{abstract}

Keywords: reactive multilayers; self-propagation; coated wires; TEM; self-healing

\section{Introduction}

The exothermic and self-propagating nature of reactive multilayers makes them promising as highly localized heat sources for several applications [1-4]. In fact, their use in joining applications and as igniters has been reported in the literature since the beginning of 21 st century, e.g., [1,5].

Reactive multilayers are "a relatively new form of energetic material that consists of a well-defined, heterogeneous structure and stored chemical energy", as defined by Adams [1]. These metastable materials are composed of tens, hundreds, or thousands of alternating individual layers of at least two elements, and have a high heat of formation and high adiabatic reaction temperature. Typically, reactive multilayers are prepared by physical vapour deposition techniques (PVD), such as sputtering or electron-beam evaporation [2]. Nanoscale multilayers, due to large interface area per unit volume, are characterized by enhanced reactivity [6,7]. For some systems and designs, reactive multilayers exhibit high temperatures and fast reactions, which could be ignited by an external energy source, such as an electric spark or mechanical load [1]. External heating initiates the reaction locally, releasing heat that promotes diffusion and intermixing in adjacent regions, driving the reaction forward in a self-sustained wave. Ni/ Al have been the most investigated Me1/Me2 (Me-metal) reactive multilayers, while particular attention has also been paid to nanoscale multilayers from the Ti-Al and Ni-Ti systems, e.g., $[4,8,9]$. 
Ignition of a self-propagating reaction in free-standing reactive multilayer foils/films is rather straightforward. However, in the presence of a coated substrate, the heat is dissipated throughout the substrate material, extinguishing the just-started reaction. Based on a 2D model, Rabinovich et al. [10] studied the self-sustaining combustion synthesis in Ni/Al multilayer films deposited on a substrate. Using the thermal model developed for the $\mathrm{Ni} / \mathrm{Al}$ multilayers' reaction, they evaluated all heat losses, and determined the minimum film thickness required for the reaction to become self-sustained.

Reactive multilayer thin foils and films have already found use as filler materials for joining applications. These fillers can be used with solder/brazing alloys or as stand-alone heat sources. The heat released by the exothermic reaction of $\mathrm{Ni} / \mathrm{Al}$ multilayer foils can be used to melt brazing alloys, e.g., $[4,11,12]$, or to enhance the diffusion bonding process by taking advantage of their exothermic and nanocrystalline character, e.g., [6,13]. Its application in the self-healing of cracks in metallic materials is new, and is the least studied. In this case, the heat released by the energetic material should melt a repairing material, which flows in and fills the crack. In this context, an interesting approach would consist in the development of an actuator using a wire coated by a reactive multilayer, and a repairing material with a low melting point. However, the deposition of alternated nanolayers onto curved surfaces such as wires is a challenge. Moreover, it is necessary to guarantee the occurrence of a self-propagating reaction upon ignition. To the best of the authors' knowledge, reactive multilayer thin films deposited onto wire substrates have never been studied in detail. The possibility of using the heat released by these reactive multilayers for self-healing purposes constitutes another innovative aspect of this work.

Therefore, this work is focused both on the deposition of reactive $\mathrm{Ni} / \mathrm{Al}$ multilayer thin films onto tungsten $(\mathrm{W})$ wires and attaining a self-sustained reaction by applying a voltage at the extremities of the coated wire. For this purpose, detailed analysis of the films' microstructure is carried out by transmission electron microscopy (TEM), after deposition by magnetron sputtering and following ignition by an electrical discharge.

\section{Materials and Methods}

$\mathrm{Ni}$ and $\mathrm{Al}$ alternated nanolayers were deposited onto $\mathrm{W}$ wires $(\phi=50 \mu \mathrm{m})$ and Si sheets by magnetron sputtering at an argon pressure of 0.4 Pa. Sputtering was carried out from $\mathrm{Al}(99.99 \%)$ and $\mathrm{Ni}\left(93 \mathrm{wt}\right.$. $\% \mathrm{Ni}, 7 \mathrm{wt}$. \% V) targets operating at $3.55 \times 10^{-2} \mathrm{~W} \mathrm{~mm}^{-2}$ and $2.22 \times 10^{-2} \mathrm{~W} \mathrm{~mm}^{-2}$, respectively. These values were selected based on previous experiments and should result in an $\mathrm{Al} / \mathrm{Ni}$ individual layer thickness ratio of 1.5 , leading to an $\mathrm{Al} / \mathrm{Ni}$ atomic ratio close to 1 . A few percent of vanadium was added to the nickel target. This element is necessary to decrease the magnetic effect of $\mathrm{Ni}$ in the plasma. The copper substrate-holder had a hole on the top surface where one end of the $\mathrm{W}$ wire was introduced. The other end of the wire was left free (Figure 1a). The substrate-holder with the $\mathrm{W}$ wire was placed on a rotating support. During the deposition process the substrate-holder under rotation passed in front of the $\mathrm{Al}$ target, and then in front of the Ni-7V target, exposing the surface of the wire alternately to the $\mathrm{Al}$ and $\mathrm{Ni}$ plasmas (Figure $1 \mathrm{~b}$ ), giving rise to a film constituted by alternate $\mathrm{Al}$ - and Ni-rich nanolayers. The rotation speed of the substrate-holder was selected to obtain a bilayer thickness (period) of $\sim 30 \mathrm{~nm}$, while the deposition time was selected to achieve a total thickness close to $4 \mu \mathrm{m}$. The thick copper substrate-holder acted as a heat sink, avoiding the increase of temperature, especially at the bottom of the wire.

The thickness of the films deposited onto Si substrates was evaluated by profilometry, allowing the multilayer period to be easily estimated. Cross-sections of multilayer-coated $\mathrm{Si}$ were prepared and analysed by field emission gun scanning electron microscopy (SEM). The surfaces of the coated Si and coated $\mathrm{W}$ wire were also observed by SEM. The SEM microscope used was manufactured by Zeiss (Oberkochen, Germany), and is equipped with an energy dispersive spectrometer (EDS) manufactured by Oxford Instruments (Abingdon, UK). The microstructure analysis was carried out with the use of Tecnai G2 FEG SuperTWIN 200 kV TEM manufactured by FEI (Eindhoven, The Netherlands) equipped with high angular annular dark field (HAADF) and EDAX detectors for STEM and EDS investigations, 
respectively. The thin foils for the TEM experiments were prepared by means of FEI Quanta 3D 200 Dual Beam Focused Ion Beam (FIB), equipped with Omniprobe lift-out system. They were cut out in such a way as to be able to observe the cross-section, and were thinned down to $\sim 100 \mathrm{~nm}$. The phase analysis was performed using selected area diffraction (SAD) patterns, which were solved with the help of ProcessDiffraction ${ }^{\circledR}$ software (Janos Labar, Budapest, Hungary).

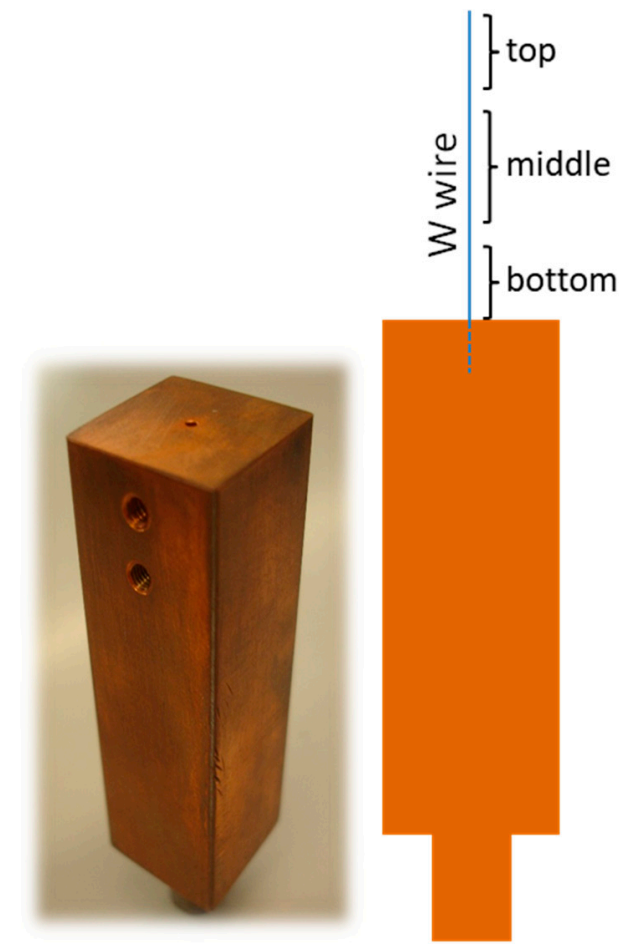

$(1: 1)$

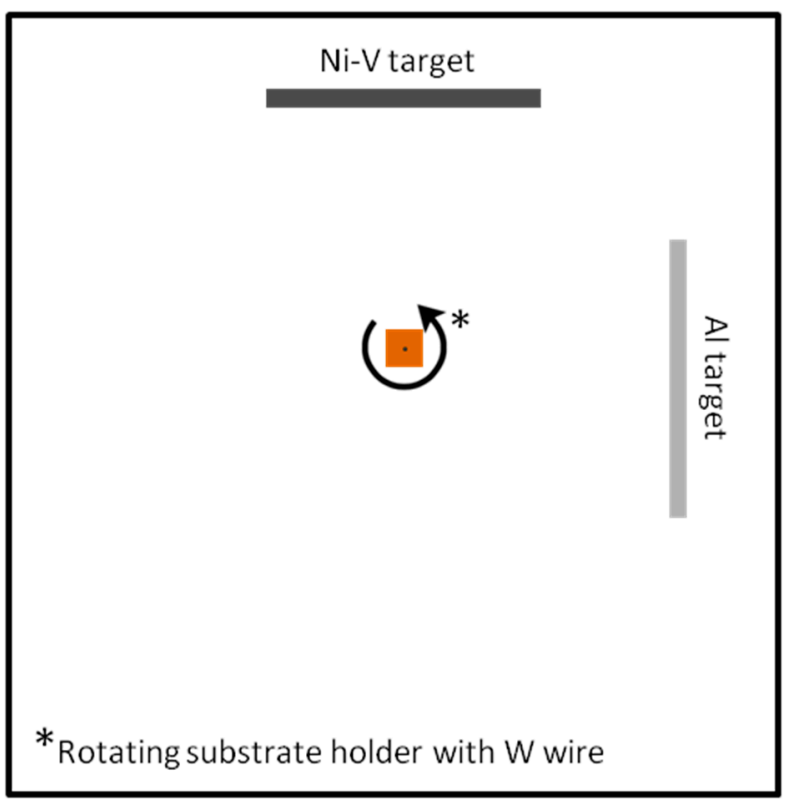

$(1: 5)$

(a)

(b)

Figure 1. (a) Copper substrate-holder showing the hole at the top surface where the $\mathrm{W}$ wire is introduced, and (b) schematics of the deposition chamber top view.

\section{Results and Discussion}

The multilayer-coated wires were characterized in the as-deposited state, as well as after ignition by applying a $9 \mathrm{~V}$ voltage.

\subsection{As-Deposited Films}

The profilometry tests on coated Si substrates revealed a total thickness of $3.8 \mu \mathrm{m}$, which was close to the desired value. Taking this into account, as well as the deposition time and the substrates' rotation speed, a modulation period of $31 \mathrm{~nm}$ was estimated. These results can be confirmed in the SEM images (Figure 2), where Ni- and Al-rich layers can be distinguished throughout the entire film's thickness. The SEM analyses show a columnar growth morphology and waviness typical for magnetron sputtered films. Although the power applied to each target was selected to achieve a near equiatomic chemical composition, the EDS results indicate an average chemical composition enriched in $\mathrm{Al}$ (it should be noted that the corrections used in EDS analysis assumes a homogeneous distribution of elements within the excited volume, and therefore, the latter result could also deviate from the real value). 


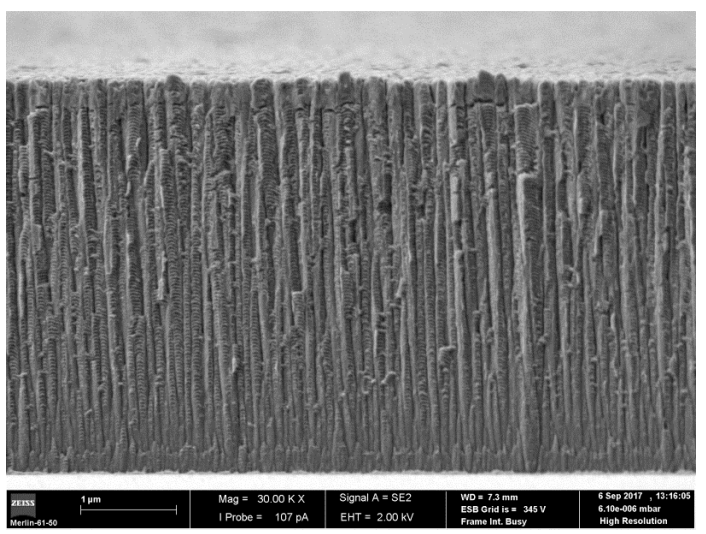

(a)

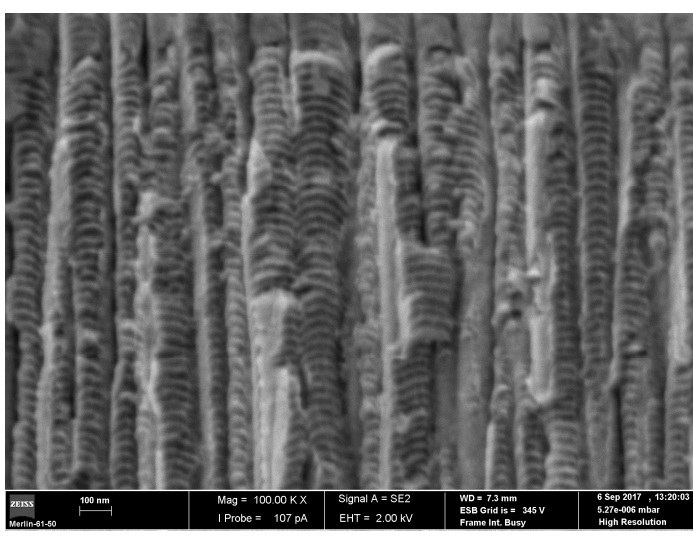

(b)

Figure 2. Cross-section images (SEM) of a Ni/ Al multilayer thin film deposited onto Si substrate at different magnifications. (a) 30,000 $\times$ and (b) 100,000 $\times$.

The deposition of multilayer thin films onto the curved surface of wires is not as straightforward as in flat mirror-polished Si substrates (length and width of a few millimetres). However, according to EDS analyses carried out on several areas $\left(\sim 4 \times 3 \mu \mathrm{m}^{2}\right)$ across the surface of the wires, the presence of $\mathrm{Ni}$ and $\mathrm{Al}$ was always detected, confirming that the wires had been successfully coated. Since the substrate-holder with the wire (Figure 1) was rotating and passing alternately in front of the Al and $\mathrm{Ni}$ targets, the whole surface of the wires was exposed to $\mathrm{Al}$ and Ni plasma, guaranteeing a uniform coating. In a preliminary work in which NiTi wires with larger diameters $(0.4$ and $0.7 \mathrm{~mm})$ were coated with multilayer thin films using the same deposition strategy, the coated wires were mounted in resin, cut and polished to obtain cross-sections for SEM analysis. SEM observation allowed us to conclude that the coatings had been deposited all around the wires, but the polishing process partially damaged the coatings. In the present work, in order to check the nanolayered structure, TEM cross-section observations were carried out. For this purpose, several thin foils were prepared from randomly selected regions of the wires. In all cases, the presence of the multilayer coating was observed. Exemplificative bright field (BF) TEM images of Ni/Al films deposited onto the curved surface of the $\mathrm{W}$ wire are shown in Figure 3 (images taken from the middle part of the wire). The films present irregular waviness and bowing out of large segments. Columns, as are usually observed across the entire thickness of sputtered films, are not present. The irregular waviness can result from the atomic shadowing effect, which should be more pronounced and always present for wire substrates. In fact, in sputtered films, the atomic shadowing could be responsible for the formation of columns, because during rotation, and for certain positions, there are atoms arriving at the substrate with low angles of incidence [14]. For the curved surface of wire substrates there are always atoms impinging the substrate at low angles of incidence, which should influence the nucleation process giving rise to an atypical morphology. The bowing out of segments of multilayers corresponds to the central part of the columns. Nevertheless, it is possible to distinguish the $\mathrm{Ni}$ - and $\mathrm{Al}$-rich nanolayers.

The result of a different nucleation and growth process on curved surfaces compared with flat substrates can also be clearly observed on the surface images. It should be noted that the magnification in the images shown in Figure 4 is the same. The surface of the Ni/ $\mathrm{Al}$ multilayer deposited onto wire is relatively rough, and shows the presence of irregular features with different dimensions, while that deposited onto flat silicon presents a smooth surface with columns of nearly the same diameter. The surface roughness of the substrates is not the same, because the Si substrates were mirror-polished, while the $\mathrm{W}$ wires were used as-received. The thermal conductivity of the substrates can also play a decisive role, but $\mathrm{Si}$ and $\mathrm{W}$ thermal conductivities are not significantly different. 


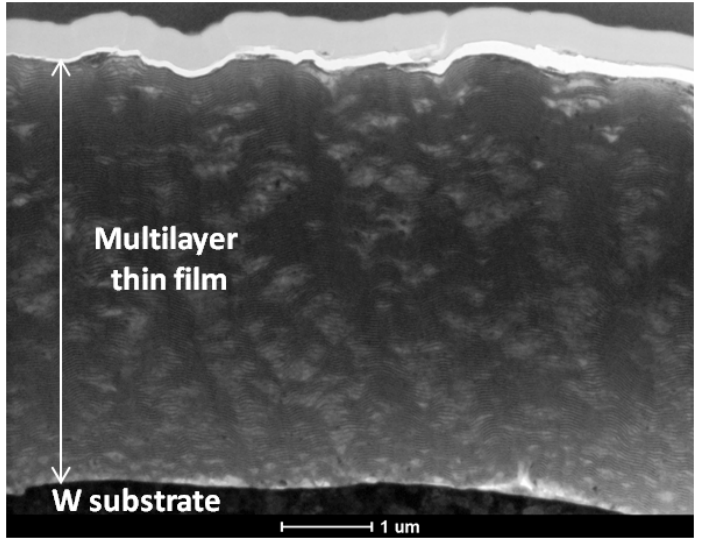

(a)

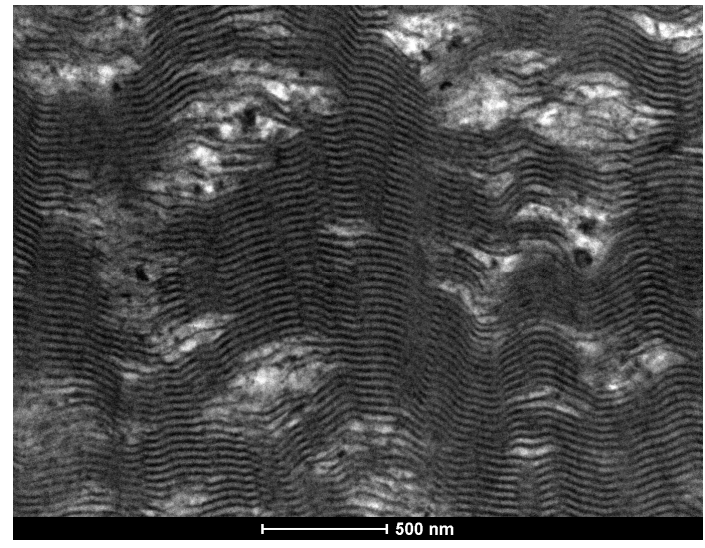

(b)

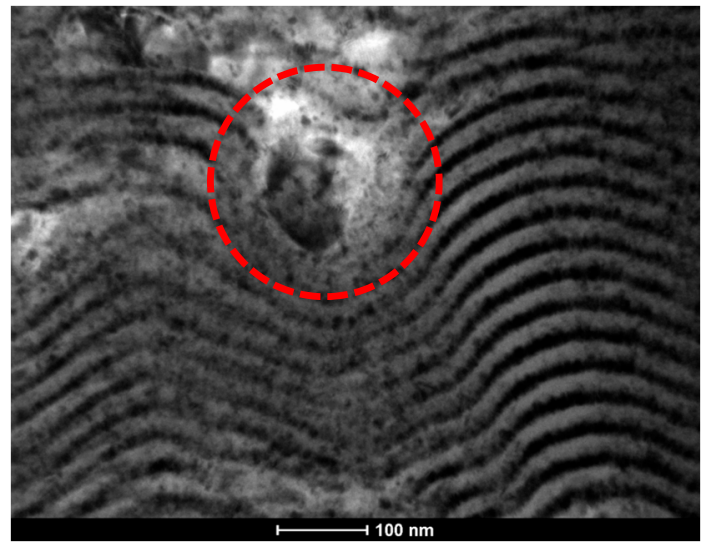

(c)

Figure 3. BF TEM micrographs of a Ni/ Al multilayer thin film deposited onto $\mathrm{W}$ wire. $(\mathbf{a}-\mathbf{c})$ Correspond to images at increasing magnifications. The red circle in the highest-magnification image corresponds to the region from which the SAD pattern in Figure 6 was obtained.

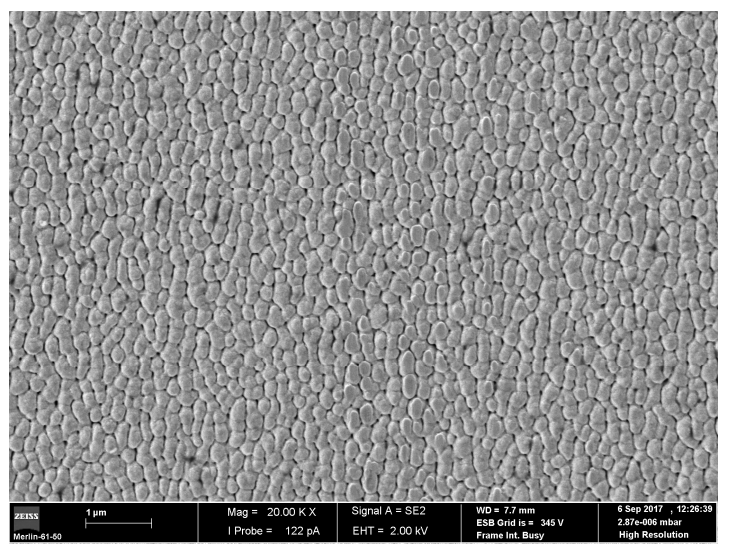

(a)

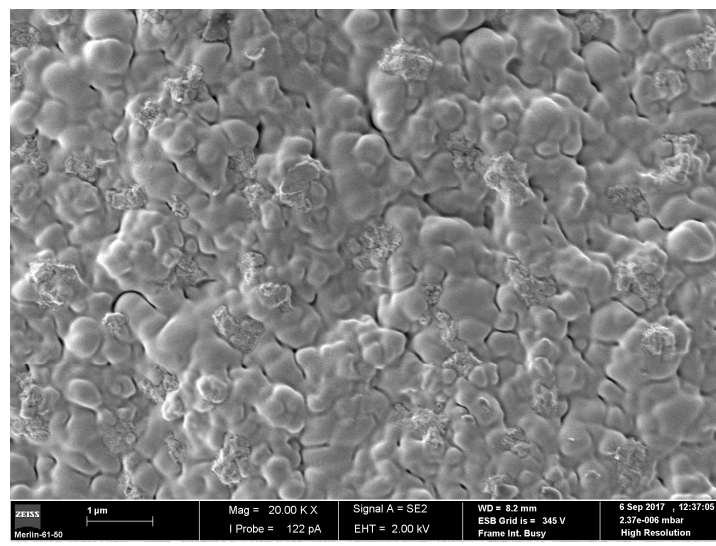

(b)

Figure 4. Surface images (SEM) of Ni/Al multilayer thin films deposited onto (a) Si flat substrates; (b) W wire curved substrates.

TEM images, aside from alternating $\mathrm{Ni}$ and $\mathrm{Al}$ layers, reveal the presence of lighter areas rich in $\mathrm{Al}$, as confirmed by the EDS profile measurements taken across these areas. The Al-rich "droplets" are absent in the films deposited onto Si, and might correspond to the small irregular features distributed 
along the surface of the films deposited onto W wire (Figure $4 \mathrm{~b}$ ). As mentioned above, this could be related to the mechanism of the film growth on the rough surface of the wires, but the possibility of the occurrence of a reaction must also be considered. The dissipation of heat through the wire substrates is not as effective as in flat substrates in full contact with the copper substrate-holder. This might be the cause of the presence of "overheated" areas that, in combination with the low reaction temperatures of $\mathrm{Ni} / \mathrm{Al}$ nanoscale multilayers $[15,16]$, could already locally promote limited reaction during deposition.

The SAD patterns of the multilayer confirmed the presence of $\mathrm{Ni}$ and $\mathrm{Al}$ major phases, but a few small peaks (appearing at the right side of Figure 5a) point to the presence of $\mathrm{Al}_{3} \mathrm{Ni}$. In Figure $5 \mathrm{~b}$, these peaks are not defined, but a small hump is still observed in this part of the spectrum, which coincides with a set of low-intensity diffraction peaks of the $\mathrm{Al}_{3} \mathrm{Ni}$ phase. During the deposition process, $\mathrm{Al}$ and $\mathrm{Ni}$ might react, leading to the formation of intermetallic phases, in particular when the substrates are not cooled (which is the present case), giving rise to higher deposition temperatures. The formation of the $\mathrm{Al}_{3} \mathrm{Ni}$ intermetallic in as-deposited $\mathrm{Ni} / \mathrm{Al}$ multilayer films has been reported [17]. As expected, the presence of intermetallic phases in the as-deposited films is more pronounced in the middle part of the wire (see Figure 1), as it is exposed to a higher average temperature than the bottom of the wire (see Figure 1), which is more efficiently cooled by the substrate-holder (Figure 5). The analysed regions corresponding to Figure 5 always comprise Al-rich droplets. However, using the smallest aperture, it was possible to analyse defect-free regions, as well as the defects occurring for the wire geometry (Figure 6). The SAD pattern of Figure 6a corresponds to a sound layered region and, as expected, only $\mathrm{Ni}$ and $\mathrm{Al}$ were identified. The SAD pattern of Figure $6 \mathrm{~b}$ was obtained from the region marked in Figure 3, and $\mathrm{Al}_{3} \mathrm{Ni}$ is indexed, indicating that the Al-rich "droplets" should correspond to this intermetallic phase. In addition to spots of the $\mathrm{Al}_{3} \mathrm{Ni}$ intermetallic, rings corresponding to pure $\mathrm{Al}$ and $\mathrm{Ni}$ could also be detected.
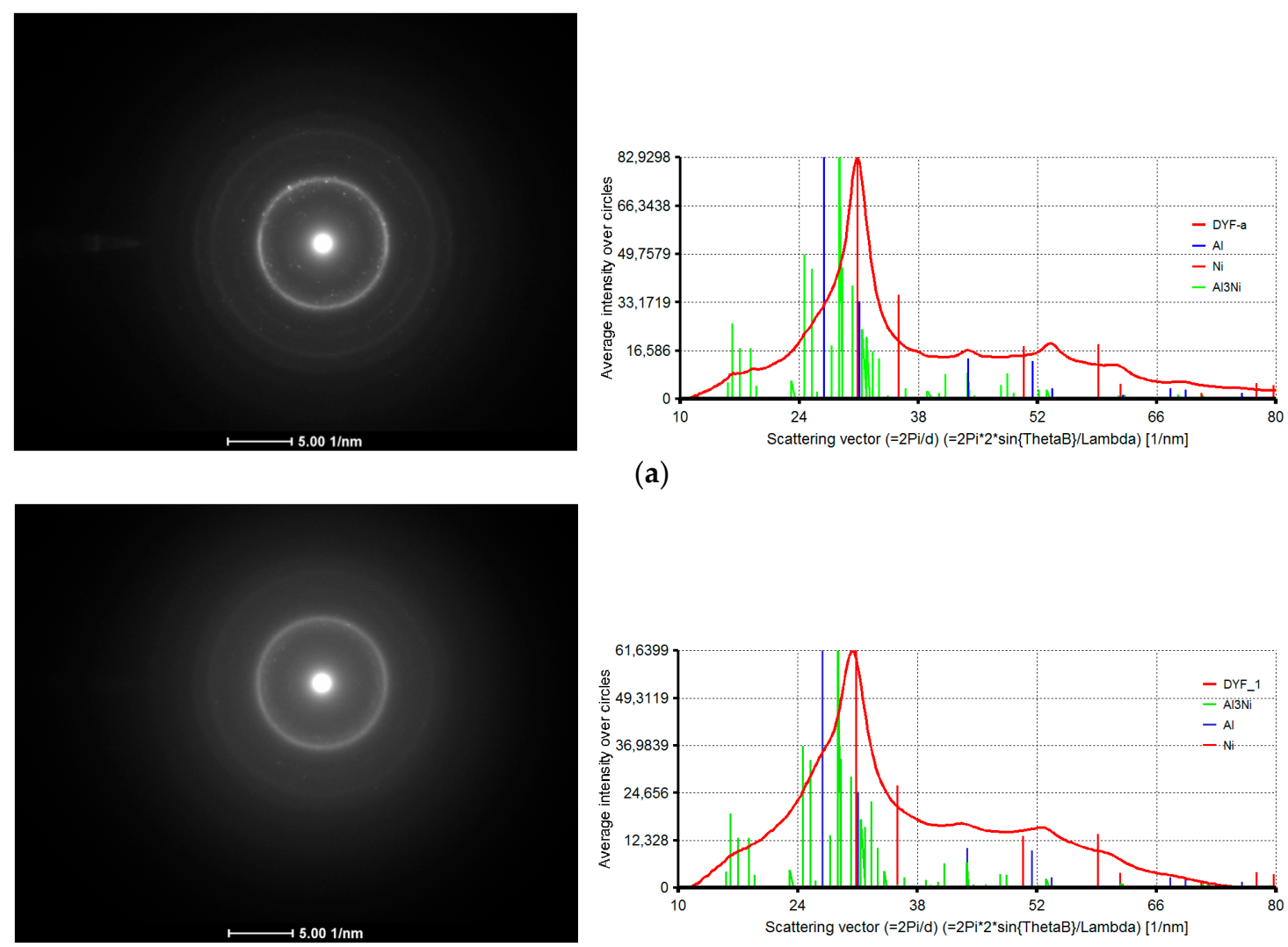

(b)

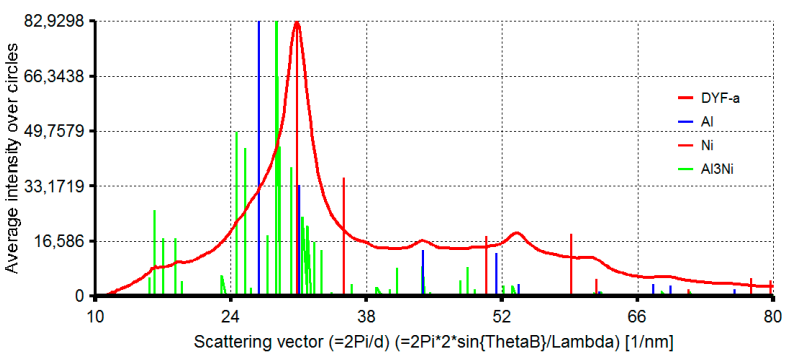

(a)

Figure 5. $\mathrm{SAD}$ patterns of $\mathrm{Ni} / \mathrm{Al}$ multilayer thin films deposited onto $\mathrm{W}$ wires and respective diffraction spectra. (a) Middle and (b) bottom part of the wire. 

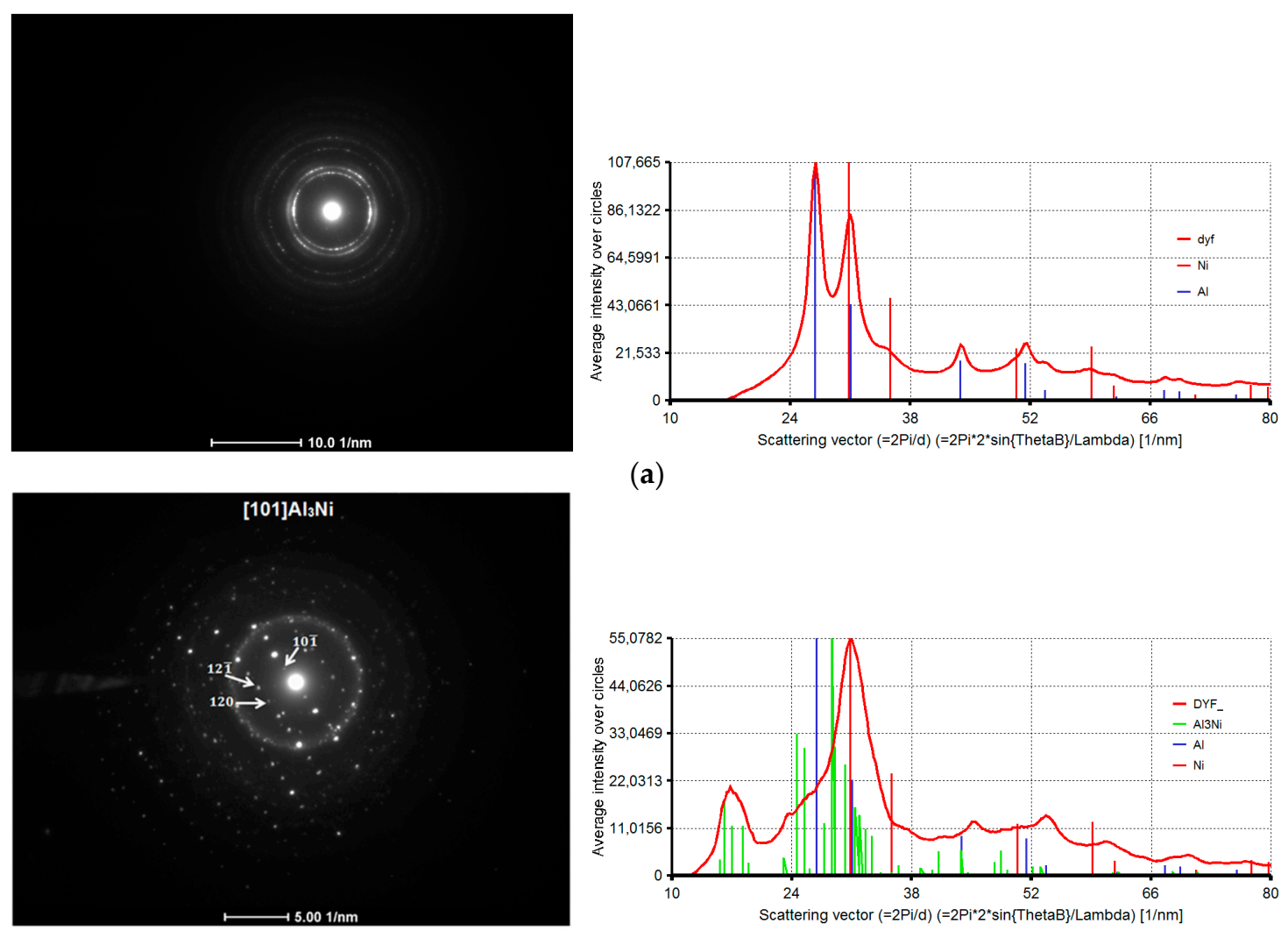

(b)

Figure 6. SAD patterns and respective diffraction spectra corresponding to (a) a defect-free region, and (b) the region marked in red in Figure 3.

The $\mathrm{Al}_{3} \mathrm{Ni}$ phase was also detected by high-resolution TEM. At the interface between $\mathrm{Al}$ and Ni layers, grains corresponding to a different phase have been detected. The indexation of Fast Fourier Transform (FFT) resulting from this phase reveals the presence of $\mathrm{Al}_{3} \mathrm{Ni}$, meaning that some intermixing occurred during the deposition process leading to the formation of intermetallic phases (Figure 7). The preferential formation of the $\mathrm{Al}_{3} \mathrm{Ni}$ phase has been frequently referred to when studying the phase evolution of $\mathrm{Ni} / \mathrm{Al}$ multilayers, especially under slow heating conditions, e.g., in [18].

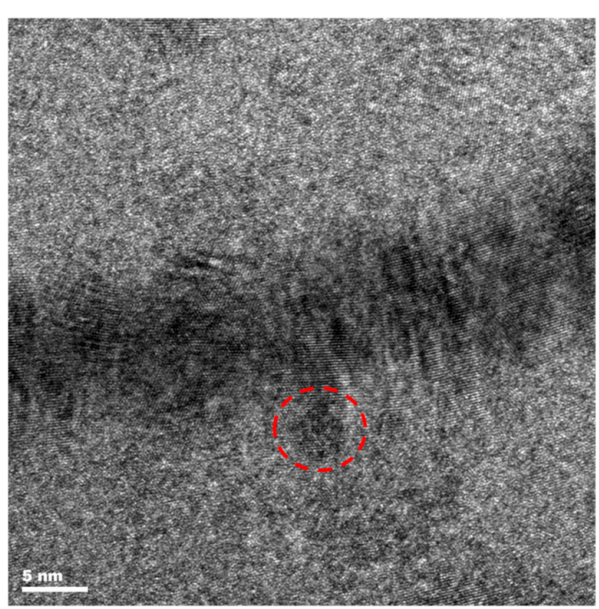

(a)

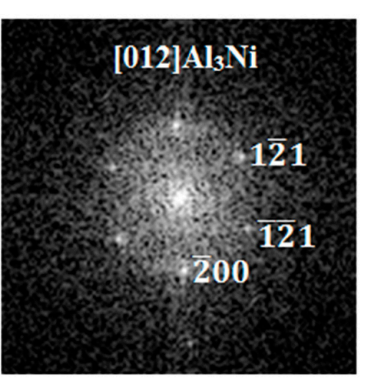

(b)

Figure 7. (a) HREM of a Ni/Al multilayer thin film, and (b) FFT of the grain marked in red. 


\subsection{Ignited Films}

The occurrence of multilayer ignition is defined as the onset of a self-propagating reaction, which could be started by applying a small burst of energy. In this work, a $9 \mathrm{~V}$ voltage was applied to the coated wires, and a bright flash was observed, indicating that a self-propagating reaction had occurred. TEM analyses showed that, upon ignition, the layered structure disappeared (Figure 8), which is proof of a $\mathrm{Ni}$ and $\mathrm{Al}$ reaction. The as-reacted microstructure is characterized by the presence of equiaxed grains whose sizes range between a few hundred nanometres and a few micrometres.
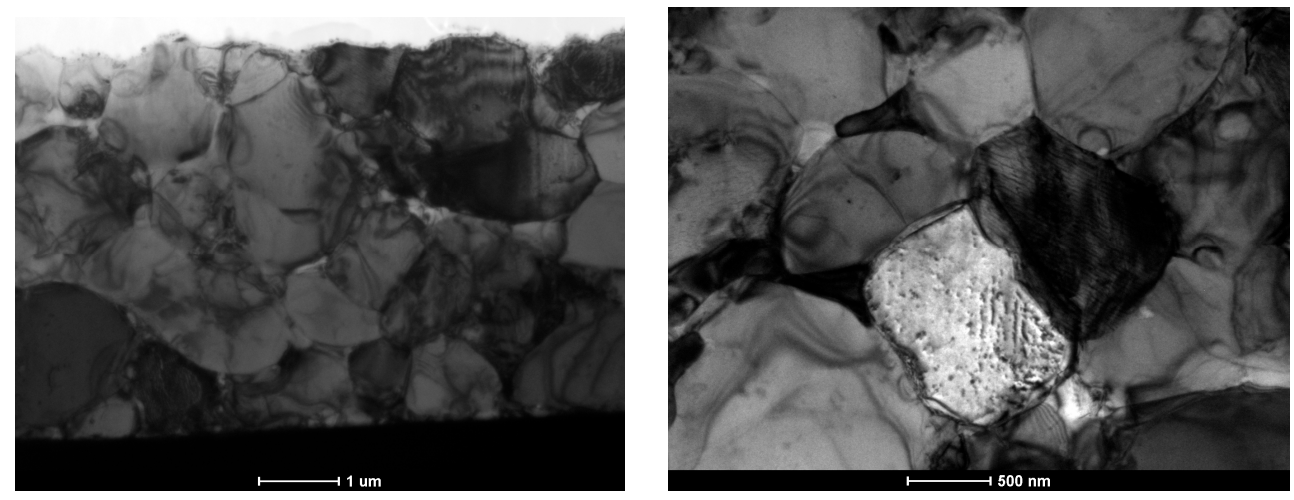

(a)

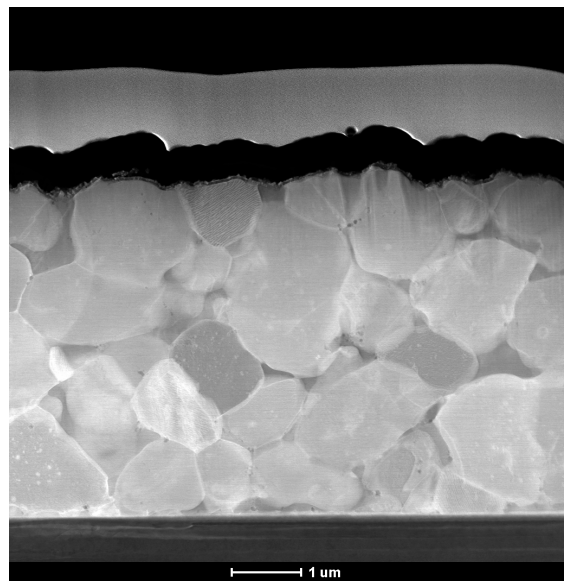

(b)

Figure 8. Micrographs (TEM) of thin films deposited onto W wires after ignition. (a) BF and (b) STEM.

Point EDS analyses were conducted inside large grains, as well as at the grain boundaries. The results summarized in Table 1 indicate $\mathrm{Al}_{3} \mathrm{Ni}_{2}$ grains with $\mathrm{Al}_{3} \mathrm{~V}$ phase located at grain boundaries.

Table 1. Average chemical composition of point TEM/EDS measurements (at. \%).

\begin{tabular}{cccc}
\hline Location & $\mathbf{A l}$ & $\mathbf{N i}$ & $\mathbf{V}$ \\
\hline Grains' centre & 59.3 & 40.3 & 0.4 \\
Intergrain areas & 75.5 & 1.3 & 22.8 \\
\hline
\end{tabular}

The as-reacted microstructure is in good agreement with that published by Trenkle et al. [19]. The formation of the $\mathrm{Al}_{3} \mathrm{Ni}_{2}$ phase is also in accordance with SEM/EDS measurements pointing to $\mathrm{Al}$ enrichment in the as-deposited multilayers. Additionally, the presence of the $\mathrm{Al}_{3} \mathrm{Ni}_{2}$ and $\mathrm{Al}_{3} \mathrm{~V}$ intermetallic phases is confirmed by SAD (Figure 9). 


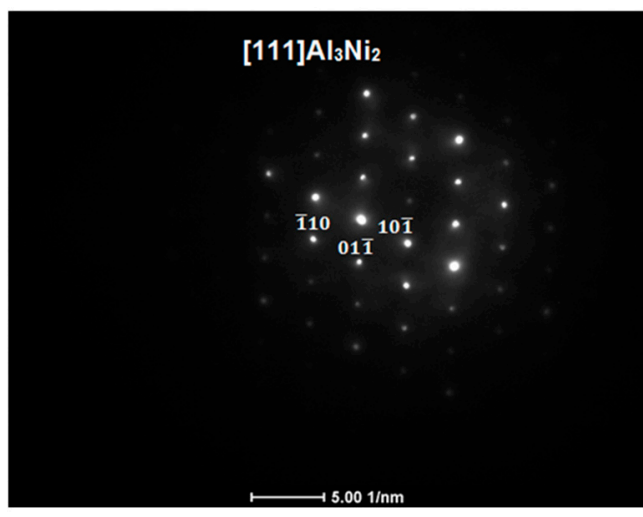

(a)

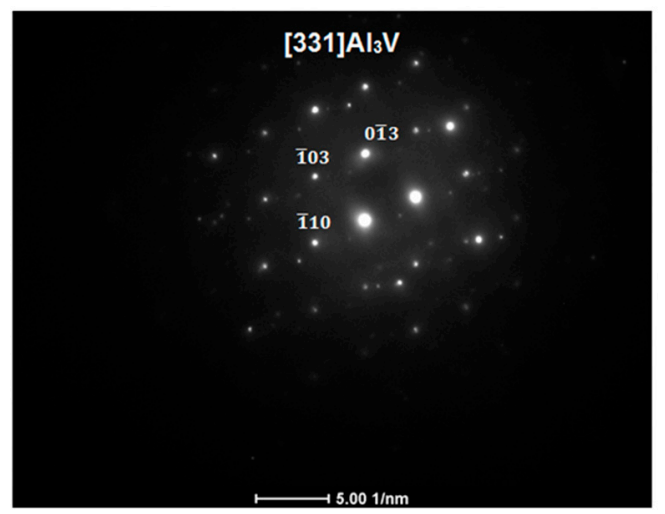

(b)

Figure 9. SAD patterns of thin films deposited onto $\mathrm{W}$ wires after ignition. (a) Grain phase and (b) intergrain phase.

The current experiments proved the possibility of obtaining heat release from reaction of $\mathrm{Ni} / \mathrm{Al}$ multilayers deposited onto tungsten wires, which has never been reported in the available literature. However, their irregular layered structure with local chemical inhomogeneities and the presence of $\mathrm{Al}_{3} \mathrm{Ni}$ in the as-deposited films decreases the heat of the reaction of such multilayers. If the objective is to promote the melting of a repairing material, the heat of the reaction must be maximized. Therefore, in future works, the deposition conditions should be optimized in order to avoid both the presence of geometric defects and premature reaction during the $\mathrm{Ni} / \mathrm{Al}$ deposition process.

\section{Conclusions}

Detailed TEM analysis of $\mathrm{Ni} / \mathrm{Al}$ multilayer thin films deposited onto $\mathrm{W}$ wires revealed a new and unique microstructure with the presence of undulation and waviness. These defects are related to the angle of incidence of the atoms arriving at the curved surface of the substrates. In addition to the distortion of the columns characteristic of sputtered films, Al-rich pockets were observed throughout the entire film thickness, which have never been observed for flat substrates. At least parts of these Al-rich areas were indexed as $\mathrm{Al}_{3} \mathrm{Ni}$. The presence of intermetallic phases in as-deposited films is favoured, because the wire substrates are not in contact with the copper substrate-holder. The removal of the geometrical defects, as well as the chemical inhomogeneities, of the reactive multilayers deposited onto $\mathrm{W}$ wire should significantly increase the overall heat released upon ignition, and allow them to be used for self-healing purposes. Even though defects are present, for the first time, self-propagation was promoted in coated wires.

Acknowledgments: This research was sponsored by FEDER funds through the program COMPETE 2020 and National Funds through FCT-Portuguese Foundation for Science and Technology, which provided financial support for CEMMPRE under the project UID/EMS/00285/2013. A.S. Ramos would like to thank FCT for the grant SFRH/BPD/109788/2015. The TEM microstructure investigations were performed within the IMMS PAS statutory project of one of the authors (Jerzy Morgiel).

Author Contributions: The work was conceived and designed by Ana Sofia Ramos and Maria Teresa Vieira. Ana Sofia Ramos prepared the multilayer thin films and performed the profilometry experiments and SEM analyses. Jerzy Morgiel and Lukasz Maj carried out the TEM observations and analysed the data. All the authors participated in the discussion of the results. Ana Sofia Ramos wrote the paper with contributions from all the other authors.

Conflicts of Interest: The authors declare no conflict of interest.

\section{References}

1. Adams, D.P. Reactive multilayers fabricated by vapor deposition: A critical review. Thin Solid Films 2015, 576, 98-128. [CrossRef] 
2. Rogachev, A.S. Exothermic reaction waves in multilayer nanofilms. Russ. Chem. Rev. 2008, 77, 21-37. [CrossRef]

3. Dreizin, E.L. Metal-based reactive nanomaterials. Prog. Energy Combust. Sci. 2009, 35, 141-167. [CrossRef]

4. Weihs, T.P. Fabrication and characterization of reactive multilayer foils and films. In Metallic Films for Electronic, Optical and Magnetic Applications-Structure, Processing and Properties, 1st ed.; Barmak, K., Coffey, K., Eds.; Woodhead Publishing Limited: Cambridge, UK, 2014; Volume 3, pp. 160-242, ISBN 978-0-85709-057-7.

5. Wang, J.; Besnoin, E.; Duckham, A.; Spey, S.J.; Reiss, M.E.; Knio, O.M.; Powers, M.; Whitener, M.; Weihs, T.P. Room-temperature soldering with nanostructured foils. Appl. Phys. Lett. 2003, 83, 3987-3989. [CrossRef]

6. Cao, J.; Feng, J.C.; Li, Z.R. Microstructure and fracture properties of reaction-assisted diffusion bonding of TiAl intermetallic with Al/Ni multilayer foils. J. Alloys Compd. 2008, 466, 363-367. [CrossRef]

7. Ramos, A.S.; Cavaleiro, A.J.; Vieira, M.T.; Morgiel, J.; Safran, G. Thermal stability of nanoscale multilayers. Thin Solid Films 2014, 571, 268-274. [CrossRef]

8. Gachon, J.-C.; Rogachev, A.S.; Grigoryan, H.E.; Illarionova, E.V.; Kuntz, J.-J.; Kovalev, D.Y.; Nosyrev, A.M.; Sachkova, N.V.; Tsygankov, P.A. On the mechanism of heterogeneous reaction and phase formation in Ti/Al multilayer nanofilms. Acta Mater. 2005, 53, 1225-1231. [CrossRef]

9. Cavaleiro, A.J.; Ramos, A.S.; Vieira, M.T.; Martins, R.M.S.; Braz Fernandes, F.M.; Morgiel, J.; Baehtz, C. Phase transformations in $\mathrm{Ni} / \mathrm{Ti}$ multilayers investigated by synchrotron radiation-based X-ray diffraction. J. Alloys Compd. 2015, 646, 1165-1171. [CrossRef]

10. Rabinovich, O.S.; Grinchuk, P.S.; Andreev, A.M.; Khina, B.B. Conditions for combustion synthesis in nanosized Ni-Al films on a substrate. Phys. Rev. B 2007, 392, 272-280. [CrossRef]

11. Duckam, A.; Spey, S.J.; Wang, J.; Reiss, M.E.; Weihs, T.P.; Besnoin, E.; Knio, O.M. Reactive nanostructured foil used as heat source for joining titanium. J. Appl. Phys. 2004, 96, 2336-2342. [CrossRef]

12. Qiu, X.; Wang, J. Bonding silicon wafers with reactive multilayer foils. Sens. Actuators A 2008, 141, $476-481$. [CrossRef]

13. Simões, S.; Viana, F.; Koçak, M.; Ramos, A.S.; Vieira, M.T.; Vieira, M.F. Diffusion bonding of TiAl using reactive Ni/Al nanolayers and Ti and Ni foils. Mater. Chem. Phys. 2011, 128, 202-207. [CrossRef]

14. Karabacak, T. Thin-film growth dynamics with shadowing and re-emission effects. J. Nanophotonics 2011, 5, 052501. [CrossRef]

15. Ramos, A.S.; Vieira, M.T.; Morgiel, J.; Grzonka, J.; Simões, S.; Vieira, M.F. Production of intermetallic compounds from $\mathrm{Ti} / \mathrm{Al}$ and $\mathrm{Ni} / \mathrm{Al}$ multilayer thin films-A comparative study. J. Alloys Compd. 2009, 484, 335-350. [CrossRef]

16. Swain, M.; Singh, S.; Basu, S.; Gupta, M. Effect of interface morphology on intermetallics formation upon annealing of Ni-Al multilayer. J. Alloys Compd. 2013, 484, 257-261. [CrossRef]

17. Manukyan, K.V.; Tan, W.; de Boer, R.J.; Stech, E.J.; Aprahamian, A.; Wiescher, M.; Rouvimov, S.; Overdeep, K.R.; Shuck, C.E.; Weihs, T.P.; et al. Irradiation-enhanced reactivity of multilayer $\mathrm{Al} / \mathrm{Ni}$ nanomaterials. ACS Appl. Mater. Interfaces 2015, 7, 11272-11279. [CrossRef] [PubMed]

18. Maj, L.; Morgiel, J.; Szlezynger, M.; Bala, P.; Cios, G. Effect of low and high heating rates on reaction path of $\mathrm{Ni}(\mathrm{V}) / \mathrm{Al}$ multilayer. Mater. Chem. Phys. 2017, 193, 244-252. [CrossRef]

19. Trenkle, J.C.; Koerner, L.J.; Tate, M.W.; Walker, N.; Gruner, S.M.; Weihs, T.P.; Hufnagel, T.C. Time-resolved $\mathrm{X}$-ray microdiffraction studies of phase transformations during rapidly propagating reactions in $\mathrm{Al} / \mathrm{Ni}$ and Zr/Ni multilayer foils. J. Appl. Phys. 2010, 107, 113511. [CrossRef]

(c) 2017 by the authors. Licensee MDPI, Basel, Switzerland. This article is an open access article distributed under the terms and conditions of the Creative Commons Attribution (CC BY) license (http://creativecommons.org/licenses/by/4.0/). 